\title{
Effective Feedback, An Essential Component of All Stages in Medical Education
}

\section{Retroalimentación efectiva, un componente esencial en todas las etapas de la educación médica}

Received: 25/11/2019 | Accepted: 11/02/2020

\author{
Angelika Kuhlmann LÜDeKE ${ }^{\mathrm{a}}$ \\ $\mathrm{MD}, \mathrm{McS}$. Director of the Department of Morphology, \\ Assistant Professor, School of Medicine, Pontificia \\ Universidad Javeriana, Bogotá, Colombia \\ Javier Fabricio Guillén Olaya \\ MD, McS. Assistant Professor, Department of \\ Morphology, School of Medicine, Pontificia \\ Universidad Javeriana, Bogotá, Colombia
}

a Corresponding author: aborda@javeriana.edu.co

How to cite: Kuhlmann Lüdeke A, Guillén Olaya JF. Effective feedback, an essential component of all stages in medical education. Univ. Med. 2020;61(3). https://doi.org/10.11144/Javeriana.umed61-3.feed

\begin{abstract}
Feedback as a teaching-learning strategy has been present in medical education for a few decades. Nonetheless, its application across the globe is considered suboptimal at best. Characteristics, conventions and recommendations for its delivery have been emphasized over the years in the literature available, but new approaches highlight the need to evaluate feedback with a greater focus on the social interaction involved and the actual impact it has on the learning process of students. Modern competency-based medical programs, with its stakeholders, staff members and educators, require a serious commitment towards its proper implementation, through robust frameworks and monitoring systems, designed according to every institution's particular needs. Preceptors and students need to be properly trained and empowered in this skill, for most effective and successful results in improving learning and performance. This effort is fundamental for trainees to acquire clinical competence according to defined standards, guarantee preparedness to work in unsupervised practice and ensure patient welfare.

Keywords

formative feedback; effective feedback; medical education.
\end{abstract}

\section{RESUMEN}

La retroalimentación como estrategia de enseñanza-aprendizaje, ha estado presente en la educación médica desde hace unas décadas. Sin embargo, se considera insuficiente su utilización en programas a nivel mundial. En la literatura disponible se han descrito características, recomendaciones e indicaciones de cómo debe ser proporcionada esta retroalimentación. Nuevos abordajes por parte de expertos hacen hincapié en la necesidad de analizar la retroalimentación desde una nueva conceptualización, con énfasis en la interacción social que implica el proceso y en el impacto real y demostrable que tiene sobre el aprendizaje de los estudiantes. Los nuevos modelos curriculares basados en competencias, sus gestores, directivas y los miembros educadores de dichos programas deben demostrar un gran compromiso con la implementación de sistemas de retroalimentación robustos, con un 
adecuado monitoreo, y diseñados según las necesidades y características particulares de cada institución. Docentes y estudiantes requieren un adecuado entrenamiento y empoderamiento en esta habilidad, con el fin de obtener resultados exitosos, en relación con el mejoramiento del aprendizaje. Este esfuerzo es fundamental, a efectos de que los futuros profesionales médicos adquieran las competencias necesarias, según los estándares de calidad estipulados, para su ejercicio profesional sin supervisión y el aseguramiento de calidad y seguridad a los pacientes.

Palabras clave

retroalimentación efectiva; retroalimentación formativa; educación médica.

\section{Introduction}

Among the contemporary recommendations given by the Carnegie Foundation for the advancement of teaching are the need to foster collaborative learning environments and deliberate opportunities for learners to engage in reflective practice. Both of these elements should be embedded in a longitudinal mentoring context, in which feedback is a fundamental element (1).

In the early 80's, Ende defined feedback as a formative teaching strategy to present information, not judgement, with the purpose of guiding learners' future performance, thus allowing students to remain on course in reaching their goals (2). Furthermore, he stated that without feedback, "mistakes go uncorrected, good performance is not reinforced and clinical competence is achieved empirically, or not at all" (p. 778) (2). In higher-education institutions, feedback is often conceived as a one-way provision of information from teacher to student, in which no mechanism is deemed necessary to ensure the information received is actually used to improve learning (3). Students' participation is limited to listening and acting on the information given, without making their own judgments, assuming that they will interpret it the same way the teacher intends (3).

Modern competency-based education programs require students to demonstrate their skills by means of measurable approaches, accomplishing an acceptable degree of consistency as proof of their competence, to practice in their future professional field and to meet the needs of the population and health care systems $(4,5)$. Trainees require access to clinical experiences and deliberate support while receiving training in the workplace, including feedback as a key element, to help them achieve their goals and the learning objectives of the program $(6,7,8)$.

\section{Definitions and Aim}

In 2002, Hesketh and Laidlaw presented feedback as a dynamic process serving the purpose of confirming positive behavior by encouraging repetition and correcting negative behavior by encouraging change (9). A decade later, Murdoch-Eaton and Sargeant elaborated more on the concept considering it a formative teaching-learning mechanism to inform and guide development, learning and improvement (10).

The purpose of feedback is to offer not only motivation for the learning process, but equally important, direction for learning in a specific content area or task, whilst serving as a guide to shape the way trainees make sense of the experiences they encounter at the workplace, in order to design a path forward $(11,12)$. It is meant to support the development of the student's capacity to assess and change the learning behavior, according to personal his/her learning needs (13).

Praising a learner may lead to reinforcement of a set of behaviors, but it does not provide details as to which of the actions should be repeated and which ones could be improved or should be avoided (14). In contrast, feedback provides trainees with relevant information on past performance and reassurance regarding competencies achieved (14). Furthermore, feedback serves to guide learning, reinforce desirable actions, identify areas for improvement and promote reflection, in order to direct future actions and behaviors more effectively $(14,15)$.

When feedback brings to light the gap between current performance and the intended goal and standards towards competency, students can plan 
for further learning and improve understanding, knowledge and skill acquisition to overcome the discrepancies $(8,12,16,17,18)$. It is important to keep in mind that the strategies applied by teachers and students to reduce the gap may be more or less effective in enhancing learning (17). Among the variables that interact with the feedback process and how effectively it is used, are engagement with the educational process, student achievement level, complexity of the task and prior knowledge (12).

Decades of scholarly literature on this theme have repeatedly evidenced the importance of feedback mechanisms in the development and enhancement of learning $(2,19)$. In Hattie and Timperley's meta-analysis, feedback is included among the top five factors influencing learners' achievements (17). In more recent literature, Harden and Laidlaw considered feedback to be one of the four key principles leading to effective learning (20). Holmboe et al. claim that lack of feedback provision is one of the most serious deficiencies in medical education, and Weinstein advocates that the more pervasive problem of insufficient feedback is that it impedes efforts to support learners in reaching their maximum potential $(21,22)$.

When students do not receive effective feedback, they need to rely solely on selfassessment to evaluate the adequacy and quality of their performance and of the clinical skills they are learning (11). This poses a serious problem, since the literature has repeatedly demonstrated the natural human tendency toward inaccuracy in self-assessment. High performers tend to underestimate themselves, while more inexperienced or overconfident learners overestimate their performance $(23,24,25)$. Furthermore, studies have demonstrated inexperienced learners as being inconsistent in identifying their own strengths and weaknesses (14). Therefore, self-assessment as judgement of performance effectiveness and maintenance of professional competence cannot be the only or even the main means to define learning needs $(11,24,26,27)$.

Providing trainees with feedback lends them the opportunity to benchmark their own assessment against external appraisal, and cultivates a reflective practice on behavior, attitude and performance (28). It is important for learners to recognize the importance of external input on their learning process, in order to be able to apply the feedback received to the development of self-assessment skills through reflective practice. The skills of reflective practice and self-assessment are essential characteristics of professional competence and require practice and persistence through deliberate opportunities $(24,29,30)$. Learning to judge themselves and the work of others and determine how their self-analysis on their performance compares to external appraisal, raises an awareness that drives the planning of further learning towards quality performance (3).

Failure to provide feedback may bring upon an additional unwanted outcome. It can be misinterpreted as an implicit approval of the learner's performance and/or knowledge $(8,14)$. Medical education characterizes itself by a system of gradual decrease in supervision. Therefore, leaving mistakes uncorrected may lead to the trainee perpetuating these errors and even teaching them to less experienced students or future learners (14).

It is for these reasons that since 2006, the body responsible for accrediting US medical schools highlights the importance of incorporating formal feedback in courses and clerkships, in order for students to acknowledge and understand their deficiencies and work towards overcoming them, with the aim of improving performance and attain competence (31).

\section{Types of feedback (see Table 1)}

Branch and Paranjape classify feedback as (32):

Brief feedback: Is usually provided daily, on an ongoing basis, related to an observed action or behavior that has just occurred.

Formal and major feedback: Involves setting aside a specific, scheduled time to discuss the learning process in a more formal encounter, usually at mid and end of rotation. 
In education, feedback can also be described as being of two main types (33):

Formative feedback: Is often offered in real time, serving the purpose of guiding learning and improvement and is non-evaluative in nature.

Summative feedback: Serves the purpose of capturing the overall competency, usually provided at the end of a clerkship and is evaluative in nature, frequently associated with scores.

Table 1.

Types of Feedback

\begin{tabular}{|l|l|}
\hline Type & Description \\
\hline Brief & $\begin{array}{l}\text { Given shortly after an observed performance and } \\
\text { on an ongoing basis }\end{array}$ \\
\hline Formal/maJor & $\begin{array}{l}\text { Regarding the learning process over a period of } \\
\text { time }\end{array}$ \\
\hline Formative & Guides learning, non-evaluative nature \\
\hline Summative & Assesses overall competency, evaluative nature \\
\hline
\end{tabular}

Levels of feedback focus (see Table 2)

Hattie and Timperley maintain that the level at which feedback is aimed determines the effectiveness of the strategy (17).

Feedback about a task or product: It is corrective in nature and the most common level at which feedback is aimed. Frequently, the feedback received is not transferable to other tasks, and if used in excess, may detract from performance. This focus leads to more trial and error strategies and less cognitive effort.

Feedback about the process needed to create a product or complete a task: Aimed primarily at information processing and is more effective than the previous level for enhancing deeper learning.

Feedback focused at the self-regulation level: Addresses aspects regarding the way learners monitor, direct and regulate their actions towards the achievement of learning goals. This level of focus implies learners' autonomy, self-regulation, self-direction and self-discipline, and along with the previous level, are more directed at attaining mastery of a task. Through feedback aimed at the self-regulation level, effective learners create internal feedback that drives their learning even further. On the contrary, less effective learners, who elicit minimal self-regulatory strategies, depend more on external sources for input and appraisal. At this level, commitment to goals is a major mediator of the effectiveness of both positive and corrective (sometimes called negative) feedback.

Feedback directed to the self: Refers to information that tends to be more judgmental in nature and proves to be ineffective in driving learning. This type of feedback should be avoided.

Table 2.

Level of Feedback Focus

\begin{tabular}{|l|l|}
\hline Focus level & Description \\
\hline Task level & $\begin{array}{l}\text { Most common, corrective nature, not transferable } \\
\text { across tasks }\end{array}$ \\
\hline Process level & Enhances deeper learning \\
\hline Self-regulation & Addresses learner's autonomy, aimed at mastering a \\
level & task \\
\hline Self level & Judgmental nature, inhibits learning \\
\hline
\end{tabular}

Kluger and DeNisi evidenced that the favorable effects of feedback on learning depend more on the level at which it is aimed and processed than on whether the feedback is positive or corrective in nature (34).

\section{Characteristics of the feedback delivered}

Feedback to be provided to a trainee must be focused on directly observed behavior or performance of a task, that is amenable to change and that can be constructively corrected by offering strategies for behavior modification $(8,18)$. In other words, insight provided by educators should be focused on learner's decisions and actions, not on intentions and/or interpretations (24). Being the direct observer of the student, the preceptor can provide real and specific examples of the actual performance and compare it to the desirable behavior according to standards, demonstrating the gap mentioned previously (24). This renders specificity to the information provided, and 
teachers can thus ensure honesty and accuracy of the feedback process $(35,36)$.

For greater effectiveness, the comments must be clear, descriptive rather than evaluative, meaningful, purposeful, compatible with the student's prior knowledge, provide logical connections when required and linked to clear and specific learning needs and goals $(8,17,36)$. Tutors require a clear understanding of the learning goals for each stage of the curriculum, in order to link performance to competency-based learning objectives, hereby increasing feedback specificity (18). Explicit suggestions must be included to either further build on strengths or overcome weaknesses $(24,37)$.

Recommendations are in place indicating that direct observation of a trainee by the same preceptor, in a number of different settings, over a reasonable time span, is desirable for the feedback process to be accurate as well as constructive $(25,38)$. In the event of serious time constrains due to, for example, short rotations, that do not allow for repeated observations, constructive input can still be provided. When multiple data of this sort are gathered from several tutors, across different rotations over time, the information obtained can create a comprehensive picture of the educational development of the learner (33).

Another important aspect to bear in mind refers to the amount of information conveyed during the encounter. When confronted with a long list of issues, students may feel overwhelmed and become disengaged from the feedback process. Therefore, it is best to prioritize the most important aspects to be covered during each session $(24,33,39)$.

Studies exploring the perceptions and expectations of feedback receivers have evidenced that the most effective feedback for sustained improvement is the one offered by content experts $(39,40,41)$. Some authors recommend that as the trainee progresses in the educational process, more experienced physicians should observe the performance and provide the corresponding input (15).

\section{Feedback delivery process}

Every feedback session to be held requires a previous and careful planning before the actual delivery of the information.

\section{Planning phase}

Students must be informed in advance that their performance and behavior are going to be observed during the length of the clerkship, and feedback is going to be provided by the observers, in encounters carefully planned beforehand and at a mutually convenient time $(15,33)$. The goals, agenda and expected outcomes of the session should be agreed upon between both parties; in this sense, students feel included and engage more favorably with the strategy (15). Expectations about the learner's engagement in self-reflection must be explicitly informed in advance $(8,29,33)$.

Choosing a quiet, private setting, in which students feel comfortable, is important to ensure an uninterrupted dialogue $(12,15,18)$. Timing of feedback is of utmost importance, and may independently influence its effectiveness (12). Timely feedback ensures that both learner and preceptor still remember the context of the observed encounter, and provides the trainee with further opportunities to practice and demonstrate improvement in subsequent patient encounters, before end of rotation (14).

Immediate feedback has been demonstrated to be more effective in supporting development of procedural and motor skills $(12,36)$. Shute also postulates that early feedback has shown to have positive effects on motivation and facilitates persistence (12). Nevertheless, adverse events with patients can render immediate feedback counterproductive, since the reflective capacity of the student might be compromised. In these more sensitive cases, postponing the feedback is desirable (33). On the other hand, transfer of knowledge or tasks involving conceptual formation are enhanced by more delayed feedback $(10,12)$. 


\section{Delivery phase}

Initiate by encouraging the student to selfassess his/her own performance and suggest remedial measures $(8,14,15,33)$. This approach serves several purposes. It may decrease the perceived harshness of the process itself, and results in corrective feedback on more acceptable sensitive aspects $(8,14,32,42)$. Additionally, the learner's degree of insight can be explored, and a shared view of the underlying issues requiring improvement can be achieved $(14,33)$.

Probing the trainee's self-appraisal might bring up aspects that the tutor was going to address as well or different issues with which the student is not satisfied, turning the feedback session into an interactive encounter $(8,14)$. This approach helps to feed forward future meetings, directing the instructor's focus of observation towards student's self-identified areas for growth (29).

A balance between positive and corrective feedback is indicated. Reinforcing correct performance through positive feedback, utilizing specific examples observed, has been demonstrated to increase confidence in students regarding their skills, prompts them to seek more feedback and fosters a more productive learning environment $(42,43)$. When corrective feedback is indicated, specific examples of the substandard behavior, skill or task and suggestions for improvement are to be provided $(42,43)$. Negative comments require support to generate positive outcomes (36).

Adopting the frequently used trend of placing challenging aspects between two compliments (also called the "feedback sandwich") is not recommended. Even tough trainees prefer this approach, studies demonstrate that it is not effective in changing learning behavior, since it allows for students to avoid focusing their attention on the greater challenges for development (44). Providing insight to learners about tutor's professional opinion on performance must be tailored to the learning objectives being addressed and the developmental stage of each student $(14,32,45)$.
During the encounter, positive communication strategies are needed. Body language and maintaining respectful language, supportive tone and descriptive wording are important aspects to keep in mind $(8,42)$.

In cases when information within the feedback delivered is complex, scaffolding proves useful to reduce the risk of the feedback being ignored by the student (36). Provision of cues, hints and even direct instruction may be needed to guide learners to the desired track. Scaffolding also includes aspects such as motivating trainees, breaking down the task into more achievable parts, offering direction and defining goals. Helping learners realize the progress already achieved towards the identified goals and the gap still requiring work, decreases uncertainty about how well they are doing in the process, and acts as a strong motivator to increase the level of effort (12).

The sessions require that tutors confirm with the students that the message being conveyed is clear and has been understood (39). Clarity of the feedback content and the link to the observed performance are essential $(42,43)$. Gaining insight in regard to student's perspectives and reactions to the feedback received has been shown to facilitate acceptance $(39,46)$.

Every feedback encounter must lead to an action plan for improvement, devised between tutor and trainee (43). Learners should offer their own ideas, and the teacher either endorses or modifies them as needed. The aim is to agree on further appropriately challenging goals, as previous ones are attained, thus fostering ongoing learning (17).

Towards the end of the session, the next appointment should be agreed upon, allowing time between encounters for students to rehearse their performance or behavior and practice the necessary changes in skills (8). Learners should also be encouraged to offer feedback on tutor's skills in delivering feedback, and teaching staff should demonstrate receptiveness for the insight and input received $(15,33)$.

Monitoring student performance on an ongoing basis is essential to determine if the information discussed during feedback meetings 
has an impact on learning, thus serving as a feed forward mechanism to adjust actions of teachers and learners (47). The most effective feedback processes involve looping back into assessment with further feedback, to determine if the insight and input given and the strategies agreed upon for advancement have led to the expected improvement in clinical performance (37).

\section{Effects of feedback}

Engaging students in dialogue with the aim of raising awareness of what is considered quality performance and aligning learning objectives, tasks and strategies for behavior modification and enhancement constitute the substrate for a collaborative learning effort $(3,18)$. Effective feedback improves learners' capacity in regard to lifelong learning, by developing skills for setting goals, monitoring own learning processes and assimilating the input towards enhancement of performance, both in the educational and future professional scenarios (13).

Veloski et al. state that feedback can change clinical performance when systematically delivered from credible sources, and practiced within a robust framework embedded in literature (48). Trainees in the medical field have characterized their learning experience as effective when a clear link exists to the provision of feedback from the teaching staff (49). Nonetheless, the application and good use of the information received through feedback demonstrates a considerable variance among students. This is possibly due to differences in the degree of acceptance and engagement with the strategy and personal outcomes of previous feedback experiences (49). Another factor that could contribute to this variability is the impact feedback has on the learner, since it is dependent on the individual desire to improve and the selfconfidence in the ability to do so (50).

Evidence has shown feedback to be a strong motivational driving force and hence, an influential factor on learning approach (51). Academic achievement and performance are directly influenced by the student's adopted learning approach. In turn, a positive relationship has been demonstrated between deep learning approach and high academic achievement $(51,52)$. Engaging effectively with feedback allows learners to incorporate longer-term changes in learning approach, to transfer knowledge to other tasks and/or performance, to apply higher-order learning skills to build on pass experiences in order to improve and to generate their own internal feedback $(6,53)$.

With an effective feedback culture in place, students learn to accept the reality that mistakes are inherent to any learning process and should be considered learning opportunities rather than failures. The role of supervisors is to support trainees in understanding these mistakes, work to improve and avoid repeating them in the future (54).

\section{Factors that promote feedback}

Several studies have explored the perception of trainees and students as to characteristics, behaviors and actions that serve as positive influential factors for feedback processes. For the purpose of this paper, they will be classified in three groups as pertaining to the teacher, the program or the learner.

\section{Pertaining to the teachers}

Demonstrate proficiency in developing an appropriate educational climate $(11,17)$.

Commitment to the professional growth of trainees, demonstrating engagement with their role as educators (55).

Acknowledgement of learning variations among students $(56,57)$.

Master deep understanding of subject matter $(11,17)$.

Demonstrate respect towards students, especially about their shortcomings, making it safe to ask for feedback $(58,59)$.

Establish an adequate context for effective feedback dynamics (55). 
Adequate timing to provide feedback, preventing student frustration to set in (17).

Willingness to encourage self-assessment and self-regulation in learners $(11,17,57)$.

Provide feedback that elicits appropriate cognitive processes and emotional responses in students, assuring credibility of the source (50).

Pertaining to the program Pertaining to the program

Feedback culture must be implicitly and explicitly embedded in the curriculum (36).

Design clinical rotations that allow for longer-term relationships between preceptor and student $(57,60)$.

Offer more consistent opportunities for direct and deliberate observation of trainee performance $(35,57,60)$.

Have a solid feedback framework in place, stating objective milestones for feedback encounters, thus increasing staff's confidence, comfort and accuracy in their appraisal (25).

Establish a system to monitor the adoption, provision and quality of the feedback process during clerkships and learners' good use of the information received $(15,20)$.

\section{Pertaining to the learners}

Adopt a feedback seeking behavior as an integral and essential educational mechanism to improve learning and behavior towards achievement of personal goals $(37,59)$.

Play an active role in the feedback dialogue and not merely as a passive receiver of information handed down by the preceptor $(11,55,61)$.

High degrees of motivation and engagement lead to positive and open disposition for feedback (11).

More senior learners take on constructively critical feedback, rather than positive, reassuring and general comments, as the most effective and useful form (10).

\section{Factors that hamper feedback}

More recent literature in this field has emphasized the need to explore the issues that might present as barriers for effective feedback encounters, since one of the major shortcomings in medical education has been to provide high quality feedback, conductive to improvement in learners' performance (56). These factors will also be classified in three groups, as pertaining the teaching staff, the curriculum or the trainees.

Pertaining to the teaching staff

Preceptors are often not included in the curricular development and implementation processes and can therefore feel uneasy as to defining expectations for students (14).

Lack of formal training in education may result in adopting inaccurate concepts of what constitutes effective feedback or inability to translate the observed behavior into feedback that is specific, constructive and non-judgmental $(14,15)$.

Current feedback exchange is frequently affected by leniency bias, since it is easier to express positive encouragement rather than constructive feedback $(14,60)$.

Inability to recognize many teaching opportunities where feedback would be indicated (49).

Lack of conflict resolution skills and proper feedback language hinders a constructive dialogue, preventing student's awareness of the potential contribution that feedback has to offer and teachers gaining insight as to how or even if the feedback is being used $(57,60,62)$.

Unawareness that a gap usually exists between the feedback delivered and the information received by the learner (63).

Placing a greater focus on assessment rather than on feedback, offering the latter at the end of a rotation, when high-stakes assessments are being taken, renders the environment inappropriate for learning, which is precisely the main purpose of feedback (24). 
Pertaining to the program

Having inconsistent standards and lacking a stable set of benchmarks (59).

Differences between the explicit feedback received through the stated curriculum and the implicit feedback received through the curriculum in action (59).

Lacking a clear and structured feedback system embedded in the curriculum, with its corresponding system to monitor its implementation $(64,65)$.

Designing short clerkships that inhibit the possibility of establishing longitudinal educational relationships over time, with multiple teachers whose busy attending schedules offer limited encounters for direct observation $(13,14,65,66,67)$.

Utilizing various feedback tools, often lacking an educational theoretical basis, acts as confounding elements for teachers $(59,65,66)$.

Most appointments in clinical settings are based on professional qualification and research experience, and rarely are teachers formally trained as medical educators, thus evidencedbased findings obtained through research are not translated into practice $(17,24,28)$.

Educators are usually placed in conflicting positions of dual roles, as feedback provider as well as assessor (11).

Lack of learner and teacher empowerment with skills required to understand, accept, value and act on feedback $(56,68)$.

\section{Pertaining to the trainees}

Student performance is influenced by learning cues; when students receive feedback from several different sources, they must often sort through these different cues to determine the ones they deem credible to act upon and discard the ones they consider, lack the necessary credibility (6).

When feedback received is incongruent and conflicting with self-appraisal, if trainees are not prepared to handle this contradiction, they tend to ignore or reject it or act on it in a superficial manner $(56,59)$.

Learners concerned with damaging the relationship with tutors because of the feedback, tend to avoid or ignore it (59).

Students fear asking for feedback, since this might make them seem insecure, incompetent or not autonomous enough (59).

Trainees can avoid seeking feedback in circumstances when it is most needed (for example after an unfavorable patient outcome) and would benefit most from the input, that is, when their performance has not reached the baseline of minimum required standards (37).

Learners interested mainly in summative assessment and grades (69).

Students not recognizing that feedback is being provided (69).

\section{Reasons to improve and new approaches to feedback}

Medical education used to be focused on the acquisition of knowledge and the length of the training program (15). Clinicians trained learners through supervision, and it was assumed that the former were competent as both practitioners and educators (18). Authority used to come along with clinical seniority. Orders were carried out without questioning their credibility, due to the hierarchy and power that traditionally has accompanied the medical education culture, with a typical unidirectional flow of information from preceptor to trainee $(58,68)$.

New curricular competency-based models have led stakeholders to reexamine standards for competent educators, requiring high-quality teachers and not solely expert clinicians (70). Authors have described the ability to provide feedback as a characteristic that defines master teachers $(71,72)$.

Despite abundant and robust literature advocating feedback as one of the most critical influences of student learning and an essential component of medical education, feedback practice in the field is still considered as suboptimal $(17,36,43,61,68)$. Reiteratively, the 
quality and quantity of direct observation in clinical training has been identified as insufficient, and students claim that they do not receive the desired and expected feedback during their clerkships $(10,39,73)$. In the UK and Australia, reports consistently identify learners as being less satisfied with assessment and feedback than with any other aspect of their study programs (3).

Even though modern medical education has taken a significant shift towards studentcentered learning, the training of teachers in the acquisition of effective formative feedback provision skills has not been emphasized enough (39). In many institutions, feedback is considered a method in which educators inform students whether they are right or wrong, without implementing a twoway communication opportunity regarding the learning process, their shortcomings and strengths (39).

Holmboe (73) states that as direct observation and feedback continue to be suboptimal, the quality of the educational experiences is undermined, leading to graduates not being optimally prepared to work in unsupervised practice. Without proper observation and tutoring of trainee's performance, errors will go uncorrected, clinical competence is at high risk of not being achieved and most importantly, patient welfare may be compromised (28).

Patients who are cared for in teaching hospitals and outpatient clinics by physicians-in-training are entitled to high-quality care and safety in the learning environment, ensured by establishing a system of proper trainee supervision and feedback (73). Training institutions have an ethical and moral responsibility to ensure patients they are receiving safe and high-quality care and ensure learners they are receiving high-quality training (74).

As stated by Norton et al., as evidence on quality teaching accumulates, poor teaching practices are highlighted; there is little evidence to suggest that teaching experience alone makes a high-quality teacher (75). Even if clinicians are not formerly trained in medical education, several studies in diverse fields demonstrate that providing feedback is a skill that can be learned and practiced by means of faculty development programs $(76,77,78)$.

Since efforts placed on determining recommendations for effective feedback delivery have proven to be insufficient for feedback practice to be embraced as it should be, new approaches and frameworks are of utmost importance (61). Several authors, in the most recent literature, have emphasized different views to give feedback the place it deserves in medical education curricula.

Adcroft (69) advocates for the focus of feedback to be placed, not on the technical process centered on the activities of teachers and learners, but rather on the social process centered on the human relationships involved, rendering it more interactive, inclusive and effective. Along this same line of thought, Boud and Molloy (3) consider feedback must be judged primarily in regard to the identifiable impact it has on learning rather than on characteristics, rituals and conventions accompanying the process. In this sense, the aim of feedback lies on the information used by the students to enhance their learning, rather than on the information transmitted by the preceptor. This signals the need for a significant shift to highlight the action of learners in relation to feedback (studentcentered) more so than the action of instructors (teacher-centered). The implementation process must shift from being the responsibility of a few to that of most educators encompassing the program, and instead of conceiving feedback as a collection of isolated facts, as a designed and deliberate sequence of educational development over time (3).

Telio et al. (61), in 2015, introduced a novel approach of conceptualizing feedback within the framework of an educational alliance. It was constructed upon the knowledge obtained from scholarly literature, seeking to conceive and incorporate feedback as a negotiation between the actors involved. It consists of a social relationship in which through dialogue, mutual understanding of the standards and goals exists, mutual trust is perceived, and an agreement is 
established regarding the actions needed to reach the learning outcomes $(55,61)$.

Considering other findings in the literature, previously pointed out as barriers in this paper, expert authors in the field recommend a feasible approach of having among the teaching staff a reasonable number of tutors trained in the provision of feedback in contrast to a more unrealistic expectation of having the whole faculty trained uniformly and consistently (60). Other authors argue that for feedback tools, to be more effective, they should be explicit to educators and trainees, include a reasonable but limited number of competencies to be assessed, and be designed as situation-specific tools $(15,33,42,43,79)$.

\section{Summary and conclusion}

Lefroy et al. (37) offered a new, more comprehensive definition of feedback that should be embraced in all institutions with modern medical education curricula. This definition states: "Helpful feedback is a supportive conversation that clarifies the trainees' awareness of their developing competencies, enhances their self-efficacy for making progress, challenges them to set objectives for improvement and facilitates their development of strategies to enable that improvement to occur" (p. 297).

Feedback, within these more novel approaches, should be considered as a method of formative assessment for learning, instead of assessment of learning. It should be established in all medical education curricula as an indispensable strategy, based on the best available evidence and within a setting of mutual respect and trust, providing assurance that preceptors and learners are working as a team towards common goals. Implementing this valuable educational mechanism with consistency, promotes a culture of continuous life-long learning, improvement and growth in achieving curricular milestones, high-quality standards for medical care, patient safety and professional satisfaction.
Adopting feedback properly enables medical educators and learners to utilize assessment experiences beyond their inherent judgmental purpose and rather, turn them into opportunities to foster learner development. Placing greater value on formative assessment and feedback is mandatory in modern medical education, in order to provide graduates with the required competencies that were not emphasized enough in traditional curricula.

Conflict of interest: none

\section{References}

1. Irby DM, Cooke M, O'Brien BC. Calls for reform of medical education by the Carnegie Foundation for the advancement of teaching. Acad Med. 2010;85(2):220-7.

2. Ende J. Feedback in clinical medical education. JAMA. 1983;250(6):777-81.

3. Boud D, Molloy E. Rethinking models of feedback for learning: the challenge of design. Assess Eval Higher Educ. 2013;38:698-712.

4. Fitzgerald JT, Burkhardt JC, Kasten SJ, et al. Assessment challenges in competency-based education: a case study in health professions education. Med Teach. 2016;38:482-90.

5. Krackov SK, Pohl H. Building expertise using the deliberate-practice curriculum-planning model. Med Teach. 2011;33(7):570-75.

6. Watling C, Driesen E, van der Vleuten CP, et al. Learning from clinical work: the roles of learning cues and credibility judgements. Med Educ. 2012;46(2):192-200.

7. Ericson KA. Deliberate practice and the acquisition and maintenance of expert performance in medicine and related domains. Acad Med. 2004;79:570-81. 
8. Chowdhury RR, Kalu G. Learning to give feedback in medical education. Obstet Gynecol. 2004;6:243-7.

9. Hesketh E, Laidlaw J. Developing the teaching instinct, 1: feedback. Med Teach. 2002;24:245-8.

10. Murdoch-Eaton D, Sargeant J. Maturational differences in undergraduate medical students' perceptions about feedback. Med Educ. 2012;46:711-21.

11. Watling CJ. Unfulfilled promises, untapped potential: feedback at the crossroads. Med Teach. 2014;36:692-7.

12. Shute VJ. Focus on formative feedback. Rev Educ Res. 2008;78:153-89.

13. Hounsell D, McCune V, Hounsell $\mathrm{J}$, et al. The quality of guidance and feedback to students. High Educ Res Develop. 2008;27 (1):55-67.

14. Gigante J, Dell M, Sharkey A. Getting beyond "good job": how to give effective feedback. Pediatrics. 2011;127(2):205-7.

15. Ramani S, Krackov SK. Twelve tips for giving feedback effectively in the clinical environment. Med Teach. 2012;34:787-91.

16. Nicol DJ, Mac Farlane-Dick D. Formative assessment and selfregulated learning: a model and seven principles of good feedback practice. Stud High Educ. 2006;31(2):199-18.

17. Hattie J, Timperley $H$. The power of feedback. Rev Educ Res. 2007;77(1):81-112.

18. Lara RF, Mogensen KM, Markuns JF. Effective feedback in the education of health professionals. Support Line. 2016;38(2):3-8.

19. Mutch A. Exploring the practice of feedback to students. Act Learn High Educ. 2003;4(24):24-38.
20. Harden RM, Laidlaw JM. Be FAIR to students: four principles that lead to more effective learning. Med Teach. 2013;35:27-31.

21. Holmboe ES, Yepes M, Williams F, et al. Feedback and the mini clinical evaluation exercise. J Gen Intern Med. 2004;19:558-61.

22. Weinstein DF. Feedback in clinical evaluation: untying the Gordian knot. Acad Med. 2015;90(5):559-61.

23. Davis DA, Mazmanian PE, Fordis $\mathrm{M}$, et al. Accuracy of physician selfassessment compared with observed measures of competence: a systematic review. JAMA. 2006; 296:1094-1102.

24. Anderson PA. Giving feedback on clinical skills: are we starving our young? J Grad Med Educ. 2012; June:154-8.

25. Kogan JR, Conforti LN, Bernabeo EC, et al. Faculty staff perception of feedback to residents after direct observation of clinical skills. Med Educ. 2012;46:201-15.

26. Regehr G, Eva K. Selfassessment, self-direction and selfregulating professional. Clin Orthop Relat Res. 2006;449:34-8.

27. Sargeant J, Armson H, Chesluk B, et al. The processes and dimensions of informed self-assessment: a conceptual model. Acad Med. 2010;85:1212-20.

28. Burgess A, Mellis C. Feedback and assessment for clinical placements: achieving the right balance. Adv Med Educ Pract. 2015;6:373-81.

29. Mann K, Gordon J, MacLeod A. Reflection and reflective practice in health professions education: a systematic review. Adv Health Sci Educ. 2009;14(4):595-621.

30. Wynia MK. The role of professionalism and self-regulation in detecting impaired or incompetent physicians. JAMA. 2010; 304:210-2. 
31. Liaison Committee on Medical Education (LCME) [internet]. 2006. Available at https://www.lcme.org.

32. Branch WT, Paranjape A. Feedback and reflection: teaching methods for clinical settings. Acad Med. 2002;77:1185-8.

33. Kritek PA. Strategies for effective feedback. Ann Am Thorac Soc. 2015 Apr;12(4):557-60.

34. Kluger AN, DeNisi A. The effects of feedback interventions on performance: a historical review, a meta-analysis and a preliminary feedback intervention theory. Psychol Bull. 1996;119(2):254-84.

35. Molloy E. Time to pause: giving and receiving feedback in clinical education. In: Delany C, Molloy E, editors. Clinical education in the health professions. Sydney: Elsevier; 2009. p. 128-46.

36. Archer J. State of the science in health professional education: effective feedback. Med Educ. 2010;44:101-8.

37. Lefroy J, Watling C, Teunissen PW, et al. Guidelines: the do's, don'ts and don't knows of feedback for clinical education. Perspect Med Educ. 2015;4:284-99.

38. Vickery AN, Lake FR. Teaching on the run tips. 10: giving feedback. Med J Aust. 2005;183(5):267-73.

39. Perera J, Lee $\mathrm{N}$, Win $\mathrm{K}$, et al. Formative feedback to students: the mismatch between faculty perceptions and student expectations. Med Teach. 2008;30:395-9.

40. Porte MC, Xeroulis G, Reznick RK, et al. Verbal feedback from an expert is more effective than self-accessed feedback about motion efficiency in learning new surgical skills. Am J Surg. 2007;193(1):105-10.

41. Bok HG, Teunissen PW, Spruijt A, et al. Clarifying students' feedback seeking behavior in clinical clerkships. Med Educ. 2013;47(3):282-91.

42. Cantillon P, Sargeant J. Giving feedback in clinical settings. BMJ. 2008;337:1292-4.

43. Krackov SK. Giving feedback. In: Dent JA, Harden RM, editors. A practical guide for medical teachers. $3^{\text {rd }}$ edition. New York: Churchill Livingstone Elsevier; 2009. p. 357-67.

44. Parkes J, Abercrombie S, Mc Carty T. Feedback sandwiches affect perceptions but not performance. Adv Health Sci Educ Theory Pract. 2013;18:397-407.

45. Thomas JD, Arnold RM. Giving feedback. J Palliat Med. 2011;14:233-9.

46. Sargeant J, Mc Naughton E, Mercer $\mathrm{S}$, et al. Providing feedback: exploring a model (emotion, content, outcomes) for facilitating multisource feedback. Med Teach. 2011;33(9):744-9.

47. Molloy E. The feedforward mechanism: a way forward in clinical learning? Med Educ. 2010;44:1157-9.

48. Veloski J, Boex JR, Grasberger MJ, et al. Systematic review of the literature on assessment, feedback and physicians' clinical performance. Med Teach. 2006;28(2):117-28.

49. Sinclair HK, Cleland JA. Undergraduate medical students: who seeks formative feedback? Med Educ. 2007;41:580-2.

50. Eva KW, Armson H, Holmboe E, et al. Factors influencing responsiveness to feedback: on the interplay between fear, confidence and reasoning processes. Adv Health Sci Educ Theory Pract. 2012;17:15-26.

51. Román S, Cuestas PJ, Fenollar P. An examination of the interrelationship between selfesteem, others' expectations, family support, learning approaches and 
academic achievement. Stud High Educ. 2008;33:127-38.

52. Kuhlmann A, Sánchez MC. Educational alignment: learningteaching approaches as influencing factors. Univ Med. 2017;58(1).

53. McMillan WJ. "Your thrust is to understand"-how academically successful students learn. Teac Higher Edu. 2010;15:1-13.

54. Chan PE, Konrad M, Gonzalez V, et al. The critical role of feedback in formative instructional practices. Interv Sch Clin. 2014;50(2):96-104.

55. Telio S, Regehr G, Ajjawi R. Feedback and the educational alliance: examining credibility judgements and their consequences. Med Educ. 2016;50:933-42.

56. Bowen L, Marshall M, Murdoch-Eaton D. Medical student perception of feedback and feedback behaviors within the context of the "Educational Alliance". Acad Med. 2017;92 (9):1303-12.

57. Watling C. Cognition, culture and credibility: demonstrating feedback in medical education. Perspect Med Educ. 2014;3:124-8.

58. Voyer S, Cuncic G, Butler DL, et al. Investigating conditions for meaningful feedback in the context of an evidenced-based feedback program. Med Educ. 2016;50(9):43-54.

59. Mann K, van del Vleuten CP, Eva $K$, et al. Tensions in informed self-assessment: how the desire for feedback and reticence to collect and use it can conflict. Acad Med. 2011;86(9):1120-7.

60. Bing-You R, Varaklis K, Hayes V, et al. The feedback tango: an integrative review and analysis of the content of the teacher-learner feedback exchange. Acad Med. 2018;93(4):657-63.
61. Telio S, Ajjawi R, Regehr G. The "Educational Alliance" as a framework for reconceptualizing feedback in medical education. Acad Med. 2015;90(5):609-14.

62. Orsmond P, Merry S. Feedback alignment: effective and ineffective links between tutors' and students' understanding of coursework feedback. Ass Eval High Educ. 2011;36(2):125-36.

63. Evans C. Making sense of assessment feedback in highereducation. Rev Educ Res. 2013;83:70-103.

64. Al-Haqwi A, Al-Wahbi A, Abdulghani $\mathrm{H}$, et al. Barriers to feedback in undergraduate medical education. Saudi Med J. 2012;33(5):557-61.

65. Al-Mously N, Nabil NM, Abdulrahman S, et al. Undergraduate medical Students' perceptions on the quality of feedback received during clinical rotations. Med Teach. 2014;36:S17-23.

66. Colthart I, Bagnall G, Evans A, et al. The effectiveness of self-assessment on the identification of learner needs, learner activity and impact on clinical practice: BEME Guide No 10. Med Teach. 2008;30(2):124-45.

67. Watling CJ, Driessen E, van der Vleuten CP, et al. Beyond individualism: a professional culture and its influence on feedback. Med Educ. 2013c;47(6):585-94.

68. Algiraigri AH. Ten tips for receiving feedback effectively in clinical practice. Med Educ online. 2014;19:25141.

69. Adcroft A. The mythology of feedback. High Educ Res Develop. 2011;30(4):405-19.

70. Srinivasan M, Li S-TT, Meyers FJ, et al. "Teaching as a competency": 
competencies for medical educators. Acad Med. 2011;86(10):1211-20.

71. Torre DM, Simpson D, Sebastian JL, et al. Learning feedback activities and high-quality teaching: perceptions of third year medical students during an impatient rotation. Acad Med. 2005;80(10):950-4.

72. Carless D. Differing perceptions in the feedback process. Stud High Educ. 2006;31(2):219-33.

73. Holmboe ES. Realizing the promise of competency-based medical education. Acad Med. 2015;90(4):411-3.

74. Egener B, McDonald W, Rosof $\mathrm{B}$, et al. Perspective: organizational professionalism: relevant competencies and behaviors. Acad Med. 2012;87:668-74.

75. Norton L, Richardson JT, Hartley J, et al. Teachers' beliefs and intentions concerning teaching in higher education. Higher Educ. 2005;50:537-71.

76. Brauch RA, Golliath C, Patterson L, et al. A qualitative study of improving preceptor feedback delivery on professionalism to postgraduate year 1 residents through education, observation and reflection. Ochsner J. 2013;13:322-6.

77. Holmboe ES, Fiebach NH, Galaty LA, et al. Effectiveness of a focused educational intervention on resident evaluations from faculty, a randomized controlled trial. J Gen Intern Med. 2001;16:427-34.

78. Junod Perron N, Nendaz M, LouisSimonet M, et al. Effectiveness of a training program in supervisors' ability to provide feedback on residents' communication skills. Adv Health Sci Educ Theory Pract. 2013;18:901-15.

79. Renting N, Gans RO, Borleffs JC, et al. A feedback system in residency to evaluate Can MEDS roles and provide high-quality feedback: exploring its application. Med Teach. 2016;38:738-45. 